Int J Biochem Cell Biol. 2011 November ; 43(11): 1550-1562. doi:10.1016/j.biocel.2011.08.005.

\title{
Notch signaling and Notch signaling modifiers
}

\author{
Michael M. Wang ${ }^{a, b, c, ~}{ }^{*}$ \\ aNeurology Service, Veterans Administration Ann Arbor Healthcare System, Ann Arbor, MI \\ 48105, USA \\ bDepartment of Neurology, University of Michigan, Ann Arbor, MI 48109-5622, USA \\ 'Department of Molecular \& Integrative Physiology, University of Michigan, Ann Arbor, MI \\ 48109-5622, USA
}

\begin{abstract}
Originally discovered nearly a century ago, the Notch signaling pathway is critical for virtually all developmental programs and modulates an astounding variety of pathogenic processes. The DSL (Delta, Serrate, LAG-2 family) proteins have long been considered canonical activators of the core Notch pathway. More recently, a wide and expanding network of non-canonical extracellular factors has also been shown to modulate Notch signaling, conferring newly appreciated complexity to this evolutionarily conserved signal transduction system. Here, I review current concepts in Notch signaling, with a focus on work from the last decade elucidating novel extracellular proteins that up- or down-regulate signal potency.
\end{abstract}

\section{Keywords}

Notch; DSL; Endocytosis; Notch dissociation; Notch inhibition; TSP2; LRP1; CCN3; MAGP; Dlk; DNER; Contactin; Periostin; EGFL7

\section{Introduction}

Investigations into Notch predate the identification of almost all signal transduction systems. In fact, we are closing in on the centennial of the discovery of Notch mutant flies by John S. Dexter in 1914 and Notch alleles by Thomas Hunt Morgan in 1917. Investigations into Notch signaling have continued at a healthy pace, with the study of model organisms such as Drosophila melanogaster and Caenorhabditis elegans leading a steady path to gene cloning (Kidd et al., 1986; Wharton et al., 1985) and functional and genetic characterization. Study of homologous genes and gene products in vertebrates including man has recently accelerated, resulting in a surge of new insights into Notch function, genetics, cell biology, and biochemistry. Many recent reviews of Notch have elegantly described the new wealth of Notch knowledge, and readers are encouraged to explore these works (Fortini, 2009; D'Souza et al., 2010; Kopan and Ilagan, 2009). Among the molecular modifiers of Notch signaling, non-canonical extracellular modulation of Notch function has received comparatively little attention. Therefore, this review will focus on new insights into extracellular proteins that alter Notch signaling after a brief overview of Notch function and signaling mechanisms.

*Correspondence address: Department of Neurology, University of Michigan, 7629 Medical Science Building II, Box 5622, 1137 Catherine St., Ann Arbor, MI 48109-5622, USA. Tel.: +1 734763 5453; fax: +1 734936 8813. micwang@umich.edu. 


\section{Notch function}

So many systems appear to utilize Notch during development, that it would perhaps be most economical to list the organ systems that do not require Notch during development. Despite the clear importance of Notch to a multitude of organ systems, two areas of historical and medical interest that deserve notation are the nervous and cardiovascular systems. Early in the history of Notch, Poulson demonstrated that absence of Notch activity in flies causes dramatic embryonic neuronal hyperplasia and deficiency of non-neuronal cells in the brain. This was the first clue that Notch plays a role in development and, in particular, is important in cell fate choice. A considerable body of evidence in mammalian model systems shows that Notch represses differentiation into neurons while promoting glial cell differentiation (Pierfelice et al., 2011) explaining in great detail how early work showed preferential expansion of neurons in the central nervous system of flies. Further work in the brain has illuminated Notch as a mediator of binary cell differentiation by lateral inhibition, a concept reiterated in numerous systems, including photoreceptors (Cagan and Ready, 1989) and vulval (Seydoux and Greenwald, 1989) patterning in the fly and nematode, respectively. The potential role of Notch in Alzheimer's dementia has been suggested due to its ability to interact with the amyloid precursor protein (Oh et al., 2005), with which Notch shares a common processing pathway.

Notch plays diverse and essential roles in cardiovascular biology. Notch and ligand null mice have distinct vascular phenotypes (Iso and Hamamori, 2003; Xue et al., 1999; Gale et al., 2004; Krebs et al., 2000; Limbourg et al., 2005; McCright et al., 2001; High et al., 2007; Uyttendaele et al., 2001; Domenga et al., 2004). These genetic studies indicate that while Notch may be important in many tissues, its role in vascular development stands out in early vertebrate embryogenesis. Based on this role, Notch has been identified as a potential cancer therapy target, guided by the hypothesis that disruption of cancer angiogenesis by Notch inhibition can inhibit tumor growth. Preclinical studies using Notch ligand (Noguera-Troise et al., 2006; Li et al., 2007) and inhibitors (Ridgway et al., 2006) have supported the possibility that targeting this pathway could specifically interfere with cancer pathogenesis.

Mutations in Notch pathway members provide compelling evidence that Notch receptors directly impact human health and pathology. Somatic gain-of-function mutations in Notch receptors have been identified in T cell acute lymphoblastic leukemia (TALL) (Weng et al., 2004). Germ-line mutations in Notch or Notch ligands result in a variety of disparate developmental syndromes, including Alagille syndrome (Oda et al., 1997; Li et al., 1997), tetralogy of Fallot (Eldadah et al., 2001), bicuspid aortic valves (Garg et al., 2005; McDaniell et al., 2006), and spondylocostal dysostosis (Bulman et al., 2000). The mechanisms of these germ-line transmitted genetic disorders have not been clearly defined, though it is widely believed that a loss of Notch function drives the disorders. NOTCH3 mutations lead to the cerebrovascular disorder CADASIL (Joutel et al., 1996), which is the most common monogenic cause of stroke and vascular dementia and is caused by degenerative changes in vascular smooth muscle. In contrast to other Notch disorders, CADASIL is unlikely to be caused by simple loss of Notch function.

\section{Signaling overview}

\subsection{Role of cell-to-cell interactions}

One of the distinguishing characteristics of Notch signaling is its requirement for two intact cells which must use independent intracellular processing machinery to fully engage the pathway. Canonical Notch signaling has classically been considered short range signaling between two adjacent cells: (1) a signal receiving cell expressing the Notch receptor at the cell surface and (2) a signal sending cell expressing a ligand. Canonical signaling requires 
direct molecular interaction between Notch and ligands expressed on adjacent cells, and, therefore, productive signaling only occurs between cells in physical contact. Intermediaterange signaling has been reported, but in most cases, signaling may be mediated by fine cell extensions that extend the length of the cell (De Joussineau et al., 2003; Renaud and Simpson, 2001; Fitzgerald and Greenwald, 1995). To productively effect signaling, the signal receiving and signal sending cells express unique molecules that ensure that the two cells maintain distinct identities.

\subsection{The signal receiving cell and Notch activation: an overview}

Notch signal receiving cells express Notch receptors (top of Fig. 1). Metazoan species express a variable number of structurally conserved and functionally related Notch-encoding genes; D. melanogaster have one Notch gene, $C$. elegans have two, and humans and mice each have four Notch genes. In all species, Notch receptors are single pass transmembrane proteins that bind to ligands that trigger a series of events leading to gene regulation in the Notch signal receiving cell (Kopan and Ilagan, 2009). Initially, Notch is generated through the secretory pathway resulting in a glycosylated, furin-processed protein. In vertebrates, furin-processing (S1) in the Golgi apparatus converts the original polypeptide into a heterodimeric protein that is joined by non-covalent interactions (Logeat et al., 1998). This heterodimeric protein interacts with Notch ligands, inducing a conformational change in the Notch extracellular domain that allows ADAM-mediated proteolytic cleavage (S2) to take place in the extracellular space close to the plasma membrane (Brou et al., 2000). This second cleavage event permits the untethering of the Notch ectodomain from the membrane after a subsequent third cleavage of Notch within the membrane. This essential cleavage (S3) is mediated by the intramembrane protease gamma-secretase (Okochi et al., 2002; Saxena et al., 2001), a multi-protein complex that mediates cleavage of multiple transmembrane proteins including the amyloid precursor protein. Cleavage at S3 allows the release of the intra-cellular domain of Notch (NICD), which migrates to the nucleus to alter transcription (Iso and Hamamori, 2003; Lubman et al., 2004). NICD is frequently difficult to detect within the nucleus (Lubman et al., 2007), likely because it contains PEST sequences that target the polypeptide for rapid degradation (Fryer et al., 2004; Tsunematsu et al., 2004). Gene activation occurs due to the formation of transcriptional complexes between NICD, the DNA-binding factor CSL (CBF1, Su(H), LAG-1), and the coactivator Mastermind (Petcherski and Kimble, 2000; Wu et al., 2000), and activation is coupled to NICD degradation (Fryer et al., 2004; Tsunematsu et al., 2004). Therefore, unlike other signaling systems, canonical Notch activation does not result in a high degree of signal amplification, since the receptor is irreversibly cleaved, dissociated and destroyed during transduction. The linear response between Notch receptor activation and transcript activation may be important in the dose sensitivity of Notch signaling.

\subsection{The signal sending cell: the site of ligand endocytosis and Notch trans-endocytosis}

Beneath the surface of this pathway, additional molecules regulate cell signaling efficiency. In particular, the role of the signal sending cell (bottom of Fig. 1) extends beyond simply expressing Notch ligands at the cell surface; emerging evidence suggests that ligands must be processed and that Notch:ligand complexes must be endocytosed into the signal sending cell for productive signaling to occur.

D. melanogaster and zebrafish mutants affecting the Notch pathway provided initial genetic evidence for a role of endocytosis in cell-cell signal (Itoh et al., 2003; Parks et al., 2000; Seugnet et al., 1997; Le Borgne et al., 2005). Surprisingly, mutant alleles that affect Notch signaling were found in genes that participate in cell endocytosis in the signal sending cell, leading to the hypothesis that ligand endocytosis and/or recycling is required for signaling. Mammalian cell systems also provide strong evidence that endocytosis of Notch receptors 
and Notch ligands plays a major role in signaling (Nichols et al., 2007). The precise machinery required for endocytic processing of ligands is still a work in progress, but certainly includes (and is not limited to) ubiquitin-, clathrin-, dynamin-, and epsin(Overstreet et al., 2004; Tian et al., 2004; Wang and Struhl, 2004; Deblandre et al., 2001; Itoh et al., 2003; Koo et al., 2005; Lai et al., 2001; Pavlopoulos et al., 2001; Yeh et al., 2001) dependent processes. One view is that two rounds of endocytosis are required, first for activation of the ligand, and second for generation of force that pulls Notch from the signal receiving cell to the signal sending cell which results in productive signal transduction. Despite significant progress in defining molecules that are required from Notch signaling, a consensus on the role of endocytosis in the signal sending cell has yet to be agreed upon.

The discovery that Notch ectodomain is found in signal sending cells in flies (Klueg and Muskavitch, 1999) and mammalian cells (Nichols et al., 2007), has generated a novel model that couples signaling to endocytosis. According to this model, endocytosis of the ligand on the signal sending cell pulls Notch from the signal receiving cell towards the signal sending cell. The mechanical force generated by this process causes a conformational change in Notch that permits protease to cleave and to ultimately activate the protein. Several lines of studies support this model. Signal sending cells that do not internalize Notch ectodomain fail to activate signaling. In addition, atomic force microscopy has revealed that endocytosis of Notch-ligand exerts enough force to pull apart the Notch heterodimer without disrupting Notch-ligand interactions (Ahimou et al., 2004).

\section{Regulatory system: Notch checks and balances}

Given the extensive evolutionary history of Notch, it is of little surprise that the regulatory mechanisms overseeing Notch signaling are complex, many times interrelated, and apparently redundant. Several excellent reviews of additional layers of Notch tuning have been written in recent years (Fortini, 2009, Kopan and Ilagan, 2009, D’Souza et al., 2010), and include: soluble DSL ligand expression, cis-ligand expression, protein glycosylation and ubiquitination, regulation of ligand and Notch expression patterns. These mechanisms, while of critical importance, will not be discussed in this review.

\section{Molecular biology of canonical receptors and ligands}

For the purposes of this discussion, we define the canonical components as Notch receptors (which in mammals include Notch1-4) and the DSL ligands (which in mammals include Jagged1-2 and Delta-like 1,3, and 4) (Fig. 2). All Notch receptors and DSL ligands are transmembrane proteins and are hence divided into extracellular and intracellular domains.

The extracellular domains are similar for both receptors and ligands. Tandem epidermal growth factor (EGF)-like domains dominate the structure of Notch and its canonical ligands in all species. Each EGF-like repeat is composed of roughly 40 amino acids, including six cysteines that are assumed to form three intra-domain disulfide bridges. Primary sequence of these motifs suggests that many of the EGF-like domains are capable of binding calcium, which can affect both protein binding and signaling (Cordle et al., 2008; Raya et al., 2004). Mammalian Notch receptors contain from 29 to 36 repeats, and the canonical ligands contain 6-16 EGF-like domains in their respective extracellular domains. Canonical ligands are defined by the presence of the DSL domain (Henderson et al., 1994; Tax et al., 1994) at the N-terminus of each protein that is necessary for signaling and cooperates with EGF-like domains of each ligand to bind and activate Notch (Shimizu et al., 1999). Binding between receptors and ligands is mediated through EGF-like domain interactions which require the DSL domain (Henderson et al., 1997; Shimizu et al., 1999). 
The negative regulatory region (NRR) of Notch, which is C-terminal to the EGF-like domains, is of critical importance in signaling (Kopan and Ilagan, 2009). This region is composed of a triplet of LIN-12-Notch repeats (LNR) and a heterodimerization domain that directly precede the transmembrane spanning region. In the absence of ligand, NRR folds to protect Notch from ADAM-mediated proteolysis. On ligand interaction, this region is believed to undergo a molecular shift, making Notch accessible to cleavage and activation (Gordon et al., 2007). According to the "lift and cut" mechanotransduction model, forces generated by ligand engagement induce a major movement of the LNR which opens the structure to proteases (Gordon et al., 2007); one alternative possibility is that upon ligand engagement, the receptor is forcibly dissociated, which removes the LNR sequences and permits ADAM-mediated cleavage (Nichols et al., 2007); another alternative is that an allosteric change that does not require force converts the negative regulatory region into an open configuration that permits ADAM cleavage (Kopan and Ilagan, 2009). The importance of this domain is underscored by genetic mutations in this region that cause cell autonomous activation of the gene which drives T cell neoplasia (Weng et al., 2004).

The general function of the intracellular domain of Notch (NICD) has been described above. In correlation with its function, the structure of this region contains the RAM (RBP-jk association module), a linker that includes a nuclear localization signal, and seven ankyrin repeats. A second nuclear localization sequence and OPA/PEST motifs that mediate protein degradation round out the C-terminus. Additional T-ALL associated mutations that drive ligand independent, pathological Notch activity have been described in the PEST sequences of NOTCH1 (Weng et al., 2004).

In contrast to Notch, canonical ligands have very short C-terminal cytoplasmic tails that follow the transmembrane domain. These sequences are not well-conserved (Pintar et al., 2007), but they contain multiple lysines that could be mono-ubiquitinated to regulate intracellular trafficking of proteins. Finally, a majority of the ligand C-terminal domains contain putative PDZ domains that may mediate intracellular protein interactions.

\section{Non-canonical regulatory proteins in Notch signaling: expansion of government}

Several observations indicate that canonical signaling is just the tip of the iceberg in the regulation of Notch. First, the widespread functions of Notch in development and in disease processes suggest that its function could be modulated in a time- and space-dependent manner by accessory proteins. Second, Notch receptors are large, containing several dozen tandem EGF-like domains, but only a few of these are known to be involved in canonical ligand binding. The evolutionary conservation of these repeats and the potential for EGFlike domains to interact with one another are consistent with the possibility that accessory proteins could bind Notch and modify signaling. Third, a wide variety of experimental observations of Notch function are, at first glance, apparently contradictory. A potential explanation for diversity of experimental findings is that different cells and even subtle changes in experimental conditions can alter a complicated web of novel modulators that converge upon Notch.

The remainder of this review focuses on secreted proteins and membrane proteins that have been shown to modulate Notch signaling (Fig. 3). We shall define non-canonical Notch ligands as secreted or membrane proteins lacking DSL that bind to and modify Notch signaling. Many of these proteins contain EGF-like domains that characterize the canonical ligands, but some share very little similarity to the canonical ligands. 


\subsection{Epidermal growth factor-like repeat containing Notch modulators}

The vertebrate DSL ligands all contain repeats of EGF-like domains, which contribute to binding to Notch (Shimizu et al., 1999). In addition, Notch has been shown to dimerize through EGF-like domains (Opherk et al., 2009; Takahashi et al., 2010). It is therefore not surprising that a high proportion of non-canonical Notch ligands contain multiple EGF-like domains.

6.1.1. Delta-like 1 and Delta-like 2-Delta-like 1 (Dlk-1/Pref-1/FA-1/ZOG) and Dlk-2 (not Dll1 and D112) are related transmembrane proteins containing six tandem extracellular EGF-like domains. These proteins also contain a DOS domain (see discussion below). Dlk-1 has been extensively studied for its ability to inhibit adipocyte development (Wang et al., 2006). Notch signaling is suppressed when the Dlk proteins are expressed in signal receiving cell (in cis with Notch) (Nueda et al., 2007; Baladron et al., 2005; Bray et al., 2008; Sanchez-Solana et al., 2011). More recent experiments show that soluble forms of the protein suppress Notch signaling in cells stimulated by immobilized canonical ligands (Sanchez-Solana et al., 2011). In addition, overall NICD1 levels are increased in fibroblasts that have been genetically depleted of Dlk1 (Sanchez-Solana et al., 2011).

Inhibition of Notch signaling is likely mediated by protein-protein interactions with Notch ectodomain. Dlk-1 binds to Notch in yeast and molecular interactions are mediated through the fifth EGF-like domain of Dlk-1 and EGF-like domains 12-13 of Notch (Baladron et al., 2005). But, Dlk-1-Notch1 interactions have not been demonstrated in cultured mammalian cells or between purified proteins. Properly folded EGF-like domains peptides derived from the primary sequence of Dlk-1, but not unfolded peptides, also decrease Notch reporter expression.

Dlk-2 also interacts selectively with the same region of Notch1 in yeast and, in contrast to Dlk-1, has also been shown to co-immunoprecipitate with participants in this pathway including Notch1 and Dlk-1 (Sanchez-Solana et al., 2011). Notwithstanding the structural similarities between Notch1 and its canonical ligands, neither Dlk-1 nor Dlk-2 binds to Jagged or Delta (Sanchez-Solana et al., 2011). Based on these findings, models of Dlk action on Notch posit that Dlk-1 or -2 block Notch signaling by binding to Notch and preventing canonical ligands from productively triggering signaling (Fig. 4).

Though molecular and cell signaling studies in cell culture have been relatively cohesive, the role of Dlk regulation of Notch signaling is complex, involving an interplay of other signaling processes and potential feedback regulation of Dlk-1 downstream from Notch (Ross et al., 2004; Ceder et al., 2008). In flies, genetic overexpression of Dlk-1 showed a variety of phenotypes including Notch-like developmental abnormalities that are exacerbated in the context of Notch mutations. Notably, the membrane form of Dlk-1 has a stronger phenotype than the soluble Dlk-1 (Bray et al., 2008). On the other hand, both the soluble form of Dlk-1 and Dlk-1 released from the membrane by ADAM-dependent processing inhibit adipogenesis in culture and in transgenic mice (Lee et al., 2003) suggesting that the adipocyte-regulating Dlk function may be independent of Notch. The role of Dlk-1 in Notch signaling is highly dependent on context, since recent studies in nematodes show that Dlk-1 can complement the loss of OSM-11, a nematode protein that enhances Notch signaling (Komatsu et al., 2008).

In addition to the need to clarify in vivo roles of Dlk-1 in Notch signaling, several questions about the interactions between Dlk-1 and Notch remain. For example, Dlk-1 and -2 interact with each other and thus may participate in a network of interrelated Notch regulatory proteins that alter signaling in a complex fashion, since each of these proteins inhibit Notch when expressed separately, yet do not affect Notch when co-expressed (Sanchez-Solana et 
al., 2011). Further work will also be required to understand what role, if any, the signal sending cell plays in Dlk-1 regulation, since a vast majority of cell-based studies have been performed without using ligand provided by cells. Finally, Notch signaling has been shown to inhibit Dlk-1 expression (Ross et al., 2004; Ceder et al., 2008) by undefined mechanisms.

6.1.2. Delta/Notch-like EGF-related receptor-Delta/Notch-like EGF-related receptor (DNER) is another trans-membrane molecule composed of linear arrays of EGF-like domains and has been best characterized as a participant in cerebellar development (Eiraku et al., 2005). In vitro models demonstrate that DNER expression in the signal sending cell and presentation of soluble DNER-Fc fusion protein bind and stimulate Notch signaling, including activation of CSL; in vivo, DNER activation of Notch in adjacent cells leads to glial differentiation (Eiraku et al., 2005), with loss of DNER (primarily in Purkinje cells) leading to abnormalities in glial morphology. Interestingly, in vivo, DNER has been shown to alter cell morphology via the CSL-independent Deltex-dependent pathway, since inhibitors of the CSL pathway do not impair its functional effects. Binding studies have implicated the first two EGF-like domains as necessary and sufficient for Notch binding (Eiraku et al., 2005). As in the case of Dlk, defining whether the actions of DNER require signal sending cells and what role the ligand sending cell plays will be critical to unraveling the molecular mechanism of this non-canonical ligand.

6.1.3. Thrombospondin 2-Thrombospondins (TSPs) are multifunctional and multimodular secreted proteins that are well-known to mediate diverse effects in context dependent fashions (Adams and Lawler, 2004). As prototypical matricellular proteins, these molecules do not structurally alter the extracellular matrix, but are localized to the extracellular space and modulate cell function. TSPs contain signature conserved elements, including a series of EGF-like domains. Both TSP1 and TSP2, the originally described members of this family, alter cellular function in a context dependent manner. These proteins were first described as anti-angiogenic factors which affect both endothelial and smooth muscle cells in culture. In many instances, the effects of TSP1 and TSP2 parallel the functions of Notch signaling, suggesting cross-talk between the two systems. The earliest clue that thrombospondins (TSPs) could participate in Notch signaling was the discovery that a soluble form of Jagged can interact with TSP1 (Aho and Uitto, 1998). More recently, aortas from TSP2 null mice were found to be deficient in canonical Notch target gene expression. Furthermore, TSP2 protein enhances the suppressive effects of Notch on cancer cell growth in co-culture assays (Meng et al., 2010). In spite of its more famous role in promoting cancer, Notch, under certain circumstances, suppresses cancer cell growth (Dotto, 2008); thus, modulators of Notch such as TSP2 could play a role suppression of cancer cell growth.

A direct action of TSP2 on Notch signaling was observed in cell signaling assays in which recombinant TSP2 added to media or transfected into NOTCH3 expressing cells enhanced activity of a NOTCH reporter in a canonical ligand-dependent fashion (Meng et al., 2009). TSP2 coprecipitates with Notch3 ectodomain and also binds directly to purified Notch3 protein (including EGF-like domains 1-11), suggesting that functional interaction with Notch is associated with physical binding. TSP2 also binds Jagged directly and with high affinity. Additional analysis of purified proteins shows that TSP2 enhances the interaction between NOTCH3 and Jagged in vitro, suggesting that it may facilitate a ternary complex that increases signaling efficiency.

The closely related protein TSP1 does not functionally activate Notch signaling and does not enhance binding between NOTCH3 and Jagged1 proteins, although the protein binds to Notch3 (Meng et al., 2009). Because of the close structural similarities between TSP1 and 
TSP2, domain swapping approaches are likely to shed light on sequences from TSP2 that are responsible for Notch binding and activation.

6.1.4. Low Density Lipoprotein Receptor-Related Protein 1-The large clearance receptor Low Density Lipoprotein Receptor-Related Protein 1 (LRP1) is another multifunctional protein with diverse physiological roles (Lillis et al., 2005). LRP1 has recently been shown to interact with Notch3 and to be required for TSP2-mediated enhancement of Notch3 signaling. LRP1 is similar to Notch in several ways; like Notch, LRP1 is a large type I trans-membrane protein that is processed intracellularly into two chains (A and B) that remain non-covalently linked. Like Notch, the ectodomain can be released from the membrane by a protease dependent process. The short intracellular domain contains docking sites for a number of adapter proteins, and it is thought that these are important for signaling and endocytosis of ligands. Like TSP2, LRP1 contains a series of structural modules that appear in a variety of secreted and transmembrane proteins. The Achain is composed of a large linear array of cysteine-rich complement-like domains, EGFlike domains, and beta-propeller domains. The smaller and simpler B-chain of LRP1 contains one beta-propeller domain followed by seven tandem EGF-like domains that are juxtaposed to the transmembrane domain.

LRP1 is essential for TSP2-dependent enhancement of Notch3 signaling (Meng et al., 2010). The TSP2 activation of Notch3 can be blocked by RAP, an inhibitor of all LRP1 functions; the TSP2 activity can also be inhibited by siRNA inhibition and by genetic ablation of LRP1. Finally, coimmunoprecipitation studies demonstrate that LRP1 B-chain mediates binding to both Notch3 ectodomain and to Jagged (Meng et al., 2010).

LRP1 is known as a clearance receptor that mediates TSP2-dependent endocytosis of matrix metalloproteinases, which plays a key role in regulation local protease concentration in the extracellular matrix (Yang et al., 2001). In striking analogy to this well-known process, LRP1 mediates TSP2-dependent endocytosis of Notch3 ectodomain into the signal sending cell. The coupling between transfer of Notch to the signal sending cell and stimulation of signaling implicates a novel pathway of Notch regulation by stimulated trans-endocytosis (Meng et al., 2010). It will be of interest in the future to determine whether LRP1/TSP2 mediates forcible conformational changes and/or dissociation of Notch that has been hypothesized to drive endocytosis-dependent signaling. Since all components of the LRP1/ TSP2/Notch axis form pair-wise interactions (e.g. LRP1 and Notch3 directly bind without added TSP2), it remains to be determined whether under some conditions, LRP1 can directly amplify Notch by itself or in collaboration with other LRP1 ligands.

6.1.5. Epidermal growth factor-like domain 7-The non-DSL protein EGF-like domain 7 (EGFL7) was originally described as a ligand for Notch after identification in a yeast two hybrid screen (Schmidt et al., 2009). This transmembrane protein contains an emilin (EMI) homology domain, two EGF-like domains, and a coiled-coil domain. Structural studies show that constructs that include EMI and EGF-like domains are sufficient for interactions with Notch, with proteins that include both of the domains exhibiting the strongest binding. EGFL7 binds to the EGF-like domains of all four Notch receptors. However, it does not bind to Jagged, although it blocked signaling in EGFL7 transfected cells exposed to immobilized Jagged. Thus, EGFL7 may compete for Jagged binding to Notch. Notably, expression of the protein in signal sending cells results in Notch binding, suggesting that the protein can modulate signaling in a paracrine fashion, but it is not yet known whether expression in the signal sending cell can modulate signaling.

Expression of the protein in neural stem cells promotes neuronal and oligodendrocyte differentiation and reduces formation of astrocytes, a function consistent with inhibited 
Notch function in the nervous system. The downregulatory effects of EGFL7 are either specific for Jagged1 or cell-type dependent, since inhibition of EGFL7 synthesis in endothelial cells reduces the activation of DLL4-stimulated reporter expression (Schmidt et al., 2009). Unlike Jagged, DLL4 forms complexes with EGFL7; these interactions are mediated by the EGF-like domains of DLL4, which is consistent with the possibility that ternary complex formation could be a requirement for signal activation; this possibility requires experimental proof.

In a recent study (Nichol et al., 2010), EGFL7 overexpressing mice exhibit a strong vascular phenotype resembling Notch inhibition, with hemorrhage and abnormalities in vascular patterning in some mice. Inhibition of EGFL7 in cultured endothelial cells produces morphogenic changes that phenocopy Notch inhibition. The cell autonomous modulation of Notch activity by EGFL7 was also examined by siRNA and overexpression approaches, which demonstrated that EGFL7 reduces pathway activation.

Yeast two-hybrid studies demonstrate interactions between EGFL7 and Notch1, Notch4, and DLL4, while co-immunoprecipitations confirm interactions with Notch1 and Notch4. In a yeast three-hybrid assay, EGFL7 could partly disrupt the interaction between DLL4 and Notch4, suggesting that competitive inhibition may play a role in its function. Overexpression of EGFL7 in mice results in lower Notch target gene expression in retina, but, in marked contrast, increases expression of many Notch markers in the whole embryo, which suggest multiple roles in Notch regulation dependent on tissue context. While the interaction between EGFL7 and Notch appears robust, further studies using purified components and coculture systems will be required to resolve functional paradoxes and mechanistic details.

\subsubsection{Weary (wry): a Drosophila protein that activates Notch-Kim and} colleagues have recently described the Wry gene product from $D$. melanogaster that was identified in a screen for fly mutants that exhibited dilated cardiomyopathy (Kim et al., 2010). The predicted protein encoded by Wry contains a series of EGF-like domains and a transmembrane domain, but does not contain a DSL domain. Cells expressing recombinant Wry were capable of aggregating cells that expressed Notch, suggesting that the Wry protein binds to Notch. In addition, S2N cells expressing Wry activated Notch in a gamma-secretase dependent fashion in a coculture assay. Interestingly, Notch signaling in mammalian C2C12 cells was not stimulated by Wry-expressing cells. In genetic studies, a series of Notch receptor and ligand constructs, expressed in a cardiac-specific manner, were capable of rescuing the mutant Wry heart phenotype. Finally, Wry expressed in cardiac tissue could rescue a similar heart phenotype induced by tissue-specific expression of siRNA against Notch ligand Serrate. Overall, this new study demonstrates that a non-DSL EGF-like domain containing protein in invertebrates is also capable of serving as a non-canonical Notch ligand. Forthcoming binding and interaction mapping may provide additional details regarding structure-function relationships. Since Drosophila is readily amenable to genetic manipulation and rapid analysis of phenotypes, Wry could potentially provide a powerful system to understand the molecular biology of non-canonical EGF-like domain-containing Notch ligands.

\subsection{Regulators of Notch without epidermal growth factor-like repeats}

Recently, additional non-canonical Notch ligands have been identified that do not contain EGF-like domains. Emerging evidence shows that a large variety of sequence motifs bind to the EGF-like domains of Notch to modify Notch function. 
6.2.1. Delta and OSM-11 motif proteins in nematodes-Recently, five secreted proteins have been identified in $C$. elegans, several of which have been implicated in Notch signaling (Komatsu et al., 2008). These proteins contain a Delta and OSM-11 motif (DOS) found in non-nematode DSL proteins but absent in nematode DSL ligands. While nonnematode Notch ligands may contain both DOS and DSL domains, $C$. elegans proteins contain either DOS or DSL domains, but not both. One of the DOS-containing proteins, OSM-11, binds to LIN-12 expressed in yeast, and genetic studies implicate OSM-11 in Notch-dependent vulval development, though direct binding in a biochemical system has not yet been performed. The DOS motif is a highly degenerate motif that is present in subsets of EGF-like domain proteins. Among vertebrate DSL ligands, all contain signature elements of DOS except DLL3, which coincidentally has not been shown to signal effectively.

Consequently, recent reviews have discussed the possibility that both DOS-containing proteins and DSL-proteins may be required for full activation of Notch (Kopan and Ilagan, 2009; D'Souza et al., 2010). One theory that awaits additional experimental testing is that DSL and DOS motifs must be presented together, and that in C. elegans, this is accomplished with a tripartite complex, while in vertebrates (whose ligands contain both elements in one ligand) a bipartite complex is sufficient.

6.2.2. CCN3-CCN3 (also known as NOV) is a member of the CCN (CYR61/CTGF/ NOV) family of secreted proteins, which mediate diverse cell-modulatory functions (Holbourn et al., 2008). Modules of CCN3 include an IGFBP domain, vWF-C homology region, TSP type 1 repeat domain, and a cysteine rich C-terminus. The first indication that CCN3 modifies Notch was in the C2/4 myoblast differentiation assay. CCN3 stimulates Notch in these cells, resulting in downregulation of serum withdrawal-induced muscle cells differentiation. CCN3 was also identified as a Notch ligand that activates canonical targets including HES (Sakamoto et al., 2002). Binding and activation of Notch require at least the TSP type 1 repeats and the C-terminal cysteine rich domain of CCN. Fragments that contain the TSP type 1 repeats without the CT domain did not bind Notch, implying that the CT domain is responsible for Notch binding (Katsuki et al., 2008). But, given the interaction between TSP1/2 with Notch, available data cannot rule out a cooperative requirement for TSP type 1 repeats and $\mathrm{CT}$ in signal activation.

Two non-overlapping EGF-like domains of Notch1 are sufficient for CCN3 interaction. The Notch ligands Delta and Serrate also bind to CCN3, albeit less avidly, to CCN. These data again implicate EGF-like domains as the regions of Notch responsible for non-canonical protein binding. $\mathrm{CCN} 3$ has been implicated in signaling since $\mathrm{CCN} 3$ deficient cells express markedly reduced HES transcripts and have blunted responses to recombinant soluble Jagged-enhanced hematopoietic precursor colony formation (Gupta et al., 2007). Studies with CCN3 have used cell autonomous systems that measure the effect of transfected CCN3 in the Notch signal receiving cell, but signaling in co-culture systems has not been examined. CCN3 appears to increase Notch via an extracellular interaction, since purified CCN3 is capable of mimicking the effects of CCN3 transfection. Thus, it is not clear presently whether $\mathrm{CCN} 3$ also affects the signal sending cell. It is possible that a signal sending cell may anchor CCN3 and provide physical forces that are theorized to drive canonical signal transduction. Alternatively, CCN3 could bridge ligand to Notch; biochemical studies and coculture techniques may be useful in establishing molecular mechanisms.

In vascular smooth muscle cells, purified recombinant CCN3 activates production of NICD, which is associated with expression of the CDK inhibitor p15 and p21. This is thought to result in attenuation of pathological smooth muscle proliferation, a pathway which has been linked to intimal hyperplasia of damaged arteries. Consistent with this, full CCN3 KO mice 
exhibit an amplified response to carotid artery ligation with a 5-fold increase in intimal growth following vessel occlusion (Shimoyama et al., 2010).

Intriguingly, at least two $\mathrm{CCN} 3$ null mice have been generated, each with differing phenotypes. The first published mouse strain in which the vWF-C domain has been deleted is embryonic lethal with incomplete penetrance and exhibits skeletal and vascular defects (Heath et al., 2008). A partial phenotype was observed in heterozygotes. A newer published mouse is phenotypically normal, save abnormal responses to vascular injury (Shimoyama et al., 2010). The second mouse is expected to not produce secreted CCN3 fragments due to deletion of the signal sequence at the N-terminus of the protein. Since the first mouse secretes a protein with deletion of only the vWF-C domain, its phenotype could conceivably result from neomorphic functions of a mutant protein. Further characterization of the effects of these mutant proteins on Notch signaling in vitro may be useful to determine the specific biochemical and developmental effects of different domains of CCN3.

6.2.3. Microfibril-associated glycoproteins 1 and 2-Microfibril-associated glycoproteins (MAGP1 and MAGP2) are relatively small proteins that contain matrix binding domains but not DSL or EGF-like domains. MAGP1 and 2 are associated with microfibrils and interact with fibrillin fragments that contain EGF-like domains (Jensen et al., 2001; Penner et al., 2002). MAGP1 may be expressed within the cell; meanwhile MAGP2 contains an RGD sequence that binds integrins and is retained in tight association with the cell membrane. Originally, MAGP2 was implicated in Notch signaling after a yeast two hybrid screen identified physical interactions with Jagged. Mapping of proteins expressed in mammalian cells demonstrates that the interaction domain of Jagged includes the EGF-like domains (Nehring et al., 2005). In addition to Jagged1, MAGP2 interacts with Jagged2 and Delta1. The closely related MAGP1 also binds to Jagged1 and Jagged2. Interestingly, MAGP2 specifically increases Jagged1 shedding in culture through an ADAM-mediated pathway. The effects of MAGP2 have been tested primarily in Jagged expressing cells transfected with MAGP2.

Importantly, these polypeptides also directly modulate Notch signaling in cell cultures when expressed in signal receiving cells (Miyamoto et al., 2006). Expression of either MAGP by transfection results in non-ADAM-dependent release of Notch1 heterodimers; once the larger portion of the extracellular domain is released, the smaller piece of Notch is subsequently cleavage by ADAM and gamma-secretase to create NICD. This is thought to result from the same processes that cause release of ectodomain by EDTA (Rand et al., 2000), although regulated non-metalloproteinase cleavage very close to the canonical furin site cannot be ruled out completely. In a cell autonomous system, MAGP2 increased the activation of Notch, but did not further potentiate canonical ligand induced signaling in the presence of signal sending cells. Apparently, MAGP activation of Notch requires expression in the signal receiving cell since providing the protein in the media or in an adjacent cell does not release or activate Notch. Unlike the case of Jagged shedding, both MAGP1 and 2 perform exhibit similar functionality on Notch. Mapping and immunoprecipitation studies show that the C-terminal end of MAGP forms a complex with EGF-like domains of Notch1.

As true for other secreted matrix proteins, MAGP proteins have been shown to regulate Notch in a context dependent fashion, since MAGP inhibits Notch in endothelial cells (Albig et al., 2008). The biochemical mechanisms that underlying the diversity of its functions remain to be elucidated. Possibilities include cofactors that differ between cells and differences in Notch isoforms tested in each of these studies. Defining precise molecular mechanisms of MAGP regulation of Notch could be particularly relevant to understanding the processes of Notch dissociation and ultra-short range effects on Notch (autocrine regulation). Moreover, as promoters of non-enzymatic Notch dissociation, they represent an 
unconventional mode of signal activation that demonstrates the versatility of the Notch system.

6.2.4. Y-Box 1-Y-Box 1 (YB-1 or YBX1) was originally described as a multifunctional cold shock protein with intracellular roles including transcriptional and translational regulation (Kohno et al., 2003). In addition, cells also express the protein in the extracellular space which reaches plasma membrane binding sites via a non-classical secretory pathway (Frye et al., 2009). YB-1 was recently found to bind to Notch3 in a yeast two hybrid screen. Subsequently, YB-1 was found to interact with a C-terminal stretch of EGF-like domains from Notch3, but did not bind to Notch1. Transfection of 293 cells with both Notch3 and YB-1 synergistically activated HES2 and a synthetic CBF reporter, but not a HES1 reporter. An antibody to YB-1 blocked the Notch activation and conditioned media from YB-1 transfected cells also activated the HES2 reporter, demonstrating that this non-canonical ligand acts in the extracellular space. Functional activation of Notch targets was blocked with gamma-secretase inhibitors. The action of YB-1 has therefore been hypothesized to be mediated by direct interactions between YB1 and Notch3 and signaling that is independent of cell presenting ligand. The activity of YB-1 in Notch1 activation was not directly determined, but if YB-1 discriminates against Notch1, it may be the first Notch ligand with strong preference for one of the receptors and for the HES2 promoter (over HES1) (Rauen et al., 2009).

YB-1 demonstrates other unique features not found in other Notch ligands; the protein does not contain EGF-like domains or other motifs that are commonly found in extracellular proteins. The N-terminal regions is enriched in alanine, glycine, and proline, followed by a cold shock domain, and ends with a C-terminus with two pairs of alternating basic/acidic stretches. Recently, treatment of animals with monoclonal antibodies to YB-1 or genetic ablation of one YB-1 allele both resulted in marked accumulation of Notch3 mRNA and protein (Raffetseder et al., 2011). Furthermore, YB-1 monoclonal antibody administration in a glomerulonephritis mouse model upregulates Notch3 and YB-1, indicating that YB-1 may participate in feedback regulation of Notch3.

6.2.5. Contactin1 and Contactin6-F3/Contactin 1 and NB3/Contactin6 were among the first class of vertebrate non-canonical Notch ligands described (Cui et al., 2004; Hu et al., 2003). These GPI-linked adhesion molecules contain familiar extracellular matrix motifs (immunoglobulin superfamily and fibronectin domains) but do not contain DSL or EGF-like domains. Functionally, F3 activates oligodendrocyte differentiation via Notch1 and Notch2 signaling that requires gamma-secretase generation of NICD, but does not require canonical CSL; F3-dependent effects of Notch in oligodendrocyte differentiation assays, rather, requires Deltex (Hu et al., 2003; Lu et al., 2008). Binding of F3 to Notch occurs on two independent stretches of Notch located in the first and third quarters of the ectodomain of Notch1, and these proteins are capable of signaling in trans (non-cell autonomously) or when presented as purified, soluble proteins. NB3 specifically binds to the third quarter of Notch1 (EGF-like domains 22-34). Interestingly, canonical DSL ligands are not active in cellular assays that utilize F3 and NB3, suggesting that the non-canonical function of these proteins plays an independent role in glial differentiation. In further support of a noncanonical effect of these ligands, F3 does not upregulate Hes-1 (Hu et al., 2003), NB3 does not activate CSL-dependent pathways (Cui et al., 2004), and the cellular targets of these ligands do not differentiate after introduction of NICD. These novel ligands again highlight the vast structure diversity of Notch ligands; understanding whether these ligands require endocytosis for action, whether they trigger Notch heterodimer dissociation, and whether they bind to EGF-like domains that overlap with canonical ligand binding sites will be of interest. 
6.2.6. Periostin-Periostin, a matricellular protein implicated in cardiovascular and bone matrix pathologies, contains an emilin domain and four fasciclin motifs. Periostin was implicated in Notch signaling (Tkatchenko et al., 2009) in studies of outflow tracts of the hearts of periostin null mice. This region of the heart had decreased expression of Notch target genes, which was attributed to increased expression of Dlk1. Subsequently, an additional mechanism of Notch regulation was implicated when it was discovered that periostin binds Notch1 through interactions with EGF-like domains (Tanabe et al., 2010). In periostin null mice, Notch1 protein is down-regulated, suggesting that periostin stabilizes Notch1 expression by binding to the protein. Localization studies show that though Notch appears inside of cells of knockout animals, the extracellular protein is deficient. These data are consistent with periostin serving a role to stabilize Notch expression, ultimately leading to increased expression at the surface. This emerging work demonstrates the possibility that multiple pathways (an indirect pathway involving activation of Dlk and a direct binding of periostin to Notch) may underlie the ability of a matricellular protein to regulate the Notch pathway. Moreover, the ability of periostin to bind and stabilize Notch presentation to the cell surface, if this is indeed functional protein, represents a novel mechanism of Notch signal regulation.

\section{Conclusions and future directions}

The impressive scope of influence of the Notch signaling systems has broadened in the last decade with the discovery of an expanded set of non-canonical modulators. Analysis of the non-canonical mechanisms may add details to the core pathway that have not yet been appreciated. For example MAGP may be a physiological regulator of Notch that utilizes a molecular mechanism (Miyamoto et al., 2006) that, prior to its discovery, was thought to be unique to cancer related mutations or to an artificial laboratory manipulation (EDTA treatment). Interestingly, the non-canonical modulators described here each may regulate Notch using diverse mechanisms (Fig. 4), though the molecular details still need refinement.

Why are there so many modulators/ligands of this pathway? For one, individual Notch modulators may be used for specific circumstances that require unique tissue and context dependent regulation that has driven the birth of new modulators during evolution. Future exploration of the mechanisms governing regulation of these modulators may reveal clues to the roles of each modulator. Another potential reason for the abundance of Notch regulators is that each regulator may have specificity for subsets of Notch receptors and ligands; more details will surely arise in the future since few of the current studies of Notch modulators have compared the modulation of different Notch receptors or ligands.

Perhaps another reason for the number of non-canonical Notch binding proteins is that they may themselves form protein networks, providing a higher level of regulation of the Notch pathway. For example, MAGP (Miyamoto et al., 2006; Nehring et al., 2005) and EGFL7 (Schmidt et al., 2009) bind to both receptors and canonical ligands. TSP2 and LRP1 also bind to both receptors and canonical ligands; moreover, TSP2 (Meng et al., 2009) and LRP1 (Meng et al., 2010) interact with each other. Dlk-1 and Dlk-2 also bind to each other (Sanchez-Solana et al., 2011). It remains unknown whether the order and stoichiometry of protein partnering influence the temporal activation of Notch activation and the magnitude of signaling. The high complexity of in vivo systems and disease pathology will make it necessary to understand how these proteins function in native protein ecosystems which likely contain multiple Notch modulators.

Additional modulating proteins will likely be found. The work summarized above suggests that several structural motifs are commonly found in non-canonical ligands, including EGFlike domains, the emilin domain, and the vWF-C domain. The systematic screening of 
proteins containing these sequences is likely to identify other protein modifiers of Notch. In the future, improvements in proteomic technology will permit identification of Notch modulators in mammalian systems that are not present in genetic screens of simple organisms or immediately evident in candidate protein approaches which are inherently limited in scope.

But, even among the group of proteins already identified, more work will be needed to extensively characterize their actions on Notch. In particular, most studies of non-canonical Notch ligands have stressed their functions in cis. Additional investigations using coculture models will be needed to clarify non-cell autonomous functions of these non-canonical ligands. This is important especially important, given the established importance of Notch in short-range cell-to-cell communication. Another future direction will be to understand the functions of these proteins in the context of extracellular protein networks.

None of these non-canonical ligands have been investigated with atomic level structural techniques. The recent availability of high resolution structures of Notch and its ligands will make it easier in the future to determine mechanisms of activation at atomic resolution, an approach that has yielded a wealth of knowledge about the core pathway (Kopan and Ilagan, 2009). With additional studies, the molecular logic underlying high affinity binding between EGF-like domains, which are useful beyond the Notch field, should be clarified in the next several years.

Finally, though these non-canonical ligands have been studied extensively at the biochemical and cellular level, increased efforts will be needed to identify the functions of these Notch modifiers in vivo in development and in human health. The availability of a wide range of conditionally mutant mice and an expanded arsenal of Notch reagents that the last century of work has made possible will be of great value in this effort.

\section{Acknowledgments}

I thank Ms. Kelly Z. Young for exceptional assistance with this manuscript, including generation of figures. Our work on Notch is supported by grants from the NIH (NS052681, NS054724, and NS062816) and a Merit Award from the Veterans Administration (5I01BX000375). The tremendous progress and subsequent voluminous literature on Notch biology makes it impossible to cite much of the work in this field in one review, and I apologize to investigators whose excellent contributions are not included in this overview.

\section{Abbreviations}

DSL

T-ALL

CADASIL

NICD

CSL

EGF

NRR

LNR

RAM

Dlk-1/Pref-1/FA-1/

ZOG
Delta, Serrate, LAG-2 family

$\mathrm{T}$ cell acute lymphoblastic leukemia

Cerebral Autosomal Dominant Arteriopathy with Subcortical Infarcts and Leukoencephalopathy

Notch intracellular domain

CBF1 Su(H) LAG-1

epidermal growth factor

negative regulatory region

LIN-12-Notch repeats

RBP-jk association module

Delta-like 1 


$\begin{array}{ll}\text { Dlk-2 } & \text { Delta-like 2 } \\ \text { DOS } & \text { Delta and OSM-11 motif } \\ \text { DNER } & \text { Delta/Notch-like EGF related receptor } \\ \text { TSP } & \text { thrombospondin } \\ \text { LRP 1 } & \text { Low Density Lipoprotein Receptor-Related Protein 1 } \\ \text { RAP } & \text { Receptor Associated Protein } \\ \text { EGFL7 } & \text { EGF-like domain 7 } \\ \text { Wry } & \text { weary } \\ \text { EMI } & \text { emilin } \\ \text { DLL4 } & \text { Delta-like 4 } \\ \text { CCN } & \text { CYR61/CTGF/NOV } \\ \text { CT } & \text { C-terminal domain } \\ \text { MAGP1/MAGP2 } & \text { microfibril-associated glycoprotein } \\ \text { YB-1/YBX1 } & \text { Y-box 1 } \\ \text { IGFBP } & \text { IGF binding protein } \\ \text { PEST } & \text { proline, glutamic acid, serine, threonine } \\ \text { OPA } & \text { glutamine-rich region } \\ \text { OSM-11 } & \text { Osmotic Avoidance Abnormal Protein 11 } \\ \text { vWF } & \text { von Willebrand factor } \\ \text { HES } & \text { Hairy and Enhancer of Split } \\ \text { CDK } & \text { cyclin dependent kinase } \\ \text { RGD } & \text { arginine, glycine, aspartic acid } \\ \text { EDTA } & \text { ethylenediaminetetraacetic acid } \\ \text { GPI } & \text { glycan phosphatidyl inositol } \\ \text { F3 } & \text { Contactin 1 } \\ \text { NB3 } & \text { Contactin 6 } \\ & \end{array}$

\section{References}

Adams JC, Lawler J. The thrombospondins. Int J Biochem Cell Biol. 2004; 36:961-8. [PubMed: 15094109]

Ahimou F, Mok LP, Bardot B, Wesley C. The adhesion force of Notch with Delta and the rate of Notch signaling. J Cell Biol. 2004; 167:1217-29. [PubMed: 15611340]

Aho S, Uitto J. Two-hybrid analysis reveals multiple direct interactions for thrombospondin 1. Matrix Biol. 1998; 17:401-12. [PubMed: 9840442]

Albig AR, Becenti DJ, Roy TG, Schiemann WP. Microfibril-associate glycoprotein-2 (MAGP-2) promotes angiogenic cell sprouting by blocking notch signaling in endothelial cells. Microvasc Res. 2008; 76:7-14. [PubMed: 18417156]

Baladron V, Ruiz-Hidalgo MJ, Nueda ML, Diaz-Guerra MJ, Garcia-Ramirez JJ, Bonvini E, et al. dlk acts as a negative regulator of Notch1 activation through interactions with specific EGF-like repeats. Exp Cell Res. 2005; 303:343-59. [PubMed: 15652348] 
Bray SJ, Takada S, Harrison E, Shen SC, Ferguson-Smith AC. The atypical mammalian ligand Deltalike homologue 1 (Dlk1) can regulate Notch signalling in Drosophila. BMC Dev Biol. 2008; 8:11. [PubMed: 18237417]

Brou C, Logeat F, Gupta N, Bessia C, LeBail O, Doedens JR, et al. A novel proteolytic cleavage involved in Notch signaling: the role of the disintegrin-metalloprotease TACE. Mol Cell. 2000; 5:207-16. [PubMed: 10882063]

Bulman MP, Kusumi K, Frayling TM, McKeown C, Garrett C, Lander ES, et al. Mutations in the human delta homologue, DLL3, cause axial skeletal defects in spondylocostal dysostosis. Nat Genet. 2000; 24:438-41. [PubMed: 10742114]

Cagan RL, Ready DF. Notch is required for successive cell decisions in the developing Drosophila retina. Genes Dev. 1989; 3:1099-112. [PubMed: 2792755]

Ceder JA, Jansson L, Helczynski L, Abrahamsson PA. Delta-like 1 (Dlk-1), a novel marker of prostate basal and candidate epithelial stem cells, is downregulated by notch signalling in intermediate/ transit amplifying cells of the human prostate. Eur Urol. 2008; 54:1344-53. [PubMed: 18375047]

Cordle J, Redfieldz C, Stacey M, van der Merwe PA, Willis AC, Champion BR, et al. Localization of the delta-like-1-binding site in human Notch-1 and its modulation by calcium affinity. J Biol Chem. 2008; 283:11785-93. [PubMed: 18296446]

Cui XY, Hu QD, Tekaya M, Shimoda Y, Ang BT, Nie DY, et al. NB-3/Notch1 pathway via Deltex1 promotes neural progenitor cell differentiation into oligodendrocytes. J Biol Chem. 2004; 279:25858-65. [PubMed: 15082708]

D'Souza B, Meloty-Kapella L, Weinmaster G. Canonical and non-canonical Notch ligands. Curr Top Dev Biol. 2010; 92:73-129. [PubMed: 20816393]

De Joussineau C, Soule J, Martin M, Anguille C, Montcourrier P, Alexandre D. Delta-promoted filopodia mediate long-range lateral inhibition in Drosophila. Nature. 2003; 426:555-9. [PubMed: 14654840]

Deblandre GA, Lai EC, Kintner C. Xenopus neuralized is a ubiquitin ligase that interacts with XDelta1 and regulates Notch signaling. Dev Cell. 2001; 1:795-806. [PubMed: 11740941]

Domenga V, Fardoux P, Lacombe P, Monet M, Maciazek J, Krebs LT, et al. Notch3 is required for arterial identity and maturation of vascular smooth muscle cells. Genes Dev. 2004; 18:2730-5. [PubMed: 15545631]

Dotto GP. Notch tumor suppressor function. Oncogene. 2008; 27:5115-23. [PubMed: 18758480]

Eiraku M, Tohgo A, Ono K, Kaneko M, Fujishima K, Hirano T, et al. DNER acts as a neuron-specific Notch ligand during Bergmann glial development. Nat Neurosci. 2005; 8:873-80. [PubMed: 15965470]

Eldadah ZA, Hamosh A, Biery NJ, Montgomery RA, Duke M, Elkins R, et al. Familial Tetralogy of Fallot caused by mutation in the jagged 1 gene. Hum Mol Genet. 2001; 10:163-9. [PubMed: $11152664]$

Fitzgerald K, Greenwald I. Interchangeability of Caenorhabditis elegans DSL proteins and intrinsic signalling activity of their extracellular domains in vivo. Development. 1995; 121:4275-82. [PubMed: 8575327]

Fortini ME. Notch signaling: the core pathway and its posttranslational regulation. Dev Cell. 2009; 16:633-47. [PubMed: 19460341]

Frye BC, Halfter S, Djudjaj S, Muehlenberg P, Weber S, Raffetseder U, et al. Y-box protein-1 is actively secreted through a non-classical pathway and acts as an extracellular mitogen. EMBO Rep. 2009; 10:783-9. [PubMed: 19483673]

Fryer CJ, White JB, Jones KA. Mastermind recruits CycC:CDK8 to phosphorylate the Notch ICD and coordinate activation with turnover. Mol Cell. 2004; 16:509-20. [PubMed: 15546612]

Gale NW, Dominguez MG, Noguera I, Pan L, Hughes V, Valenzuela DM, et al. Haploinsufficiency of delta-like 4 ligand results in embryonic lethality due to major defects in arterial and vascular development. Proc Natl Acad Sci U S A. 2004; 101:15949-54. [PubMed: 15520367]

Garg V, Muth AN, Ransom JF, Schluterman MK, Barnes R, King IN, et al. Mutations in NOTCH1 cause aortic valve disease. Nature. 2005; 437:270-4. [PubMed: 16025100]

Gordon WR, Vardar-Ulu D, Histen G, Sanchez-Irizarry C, Aster JC, Blacklow SC. Structural basis for autoinhibition of Notch. Nat Struct Mol Biol. 2007; 14:295-300. [PubMed: 17401372] 
Gupta R, Hong D, Iborra F, Sarno S, Enver T. NOV (CCN3) functions as a regulator of human hematopoietic stem or progenitor cells. Science. 2007; 316:590-3. [PubMed: 17463287]

Heath E, Tahri D, Andermarcher E, Schofield P, Fleming S, Boulter CA. Abnormal skeletal and cardiac development, cardiomyopathy, muscle atrophy and cataracts in mice with a targeted disruption of the Nov (Ccn3) gene. BMC Dev Biol. 2008; 8:18. [PubMed: 18289368]

Henderson ST, Gao D, Christensen S, Kimble J. Functional domains of LAG-2, a putative signaling ligand for LIN-12 and GLP-1 receptors in Caenorhabditis elegans. Mol Biol Cell. 1997; 8:175162. [PubMed: 9307971]

Henderson ST, Gao D, Lambie EJ, Kimble J. lag-2 may encode a signaling ligand for the GLP-1 and LIN-12 receptors of $C$. elegans. Development. 1994; 120:2913-24. [PubMed: 7607081]

High FA, Zhang M, Proweller A, Tu L, Parmacek MS, Pear WS, et al. An essential role for Notch in neural crest during cardiovascular development and smooth muscle differentiation. J Clin Invest. 2007; 117:353-63. [PubMed: 17273555]

Holbourn KP, Acharya KR, Perbal B. The CCN family of proteins: structure-function relationships. Trends Biochem Sci. 2008; 33:461-73. [PubMed: 18789696]

Hu QD, Ang BT, Karsak M, Hu WP, Cui XY, Duka T, et al. F3/contactin acts as a functional ligand for Notch during oligodendrocyte maturation. Cell. 2003; 115:163-75. [PubMed: 14567914]

Iso T, Hamamori YKL. HES and HERP families: multiple effectors of the Notch signaling pathway. $\mathbf{J}$ Cell Physiol. 2003; 194:237-55. [PubMed: 12548545]

Itoh M, Kim CH, Palardy G, Oda T, Jiang YJ, Maust D, et al. Mind bomb is a ubiquitin ligase that is essential for efficient activation of Notch signaling by Delta. Dev Cell. 2003; 4:67-82. [PubMed: 12530964]

Jensen SA, Reinhardt DP, Gibson MA, Weiss AS. Protein interaction studies of MAGP-1 with tropoelastin and fibrillin-1. J Biol Chem. 2001; 276:39661-6. [PubMed: 11481325]

Joutel A, Corpechot C, Ducros A, Vahedi K, Chabriat H, Mouton P, et al. Notch3 mutations in CADASIL, a hereditary adult-onset condition causing stroke and dementia. Nature. 1996; 383:707-10. [PubMed: 8878478]

Katsuki Y, Sakamoto K, Minamizato T, Makino H, Umezawa A, Ikeda MA, et al. Inhibitory effect of $\mathrm{CT}$ domain of $\mathrm{CCN} 3 / \mathrm{NOV}$ on proliferation and differentiation of osteogenic mesenchymal stem cells, Kusa-A1. Biochem Biophys Res Commun. 2008; 368:808-14. [PubMed: 18275847]

Kidd S, Kelley MR, Young MW. Sequence of the notch locus of Drosophila melanogaster: relationship of the encoded protein to mammalian clotting and growth factors. Mol Cell Biol. 1986; 6:3094-108. [PubMed: 3097517]

Kim IM, Wolf MJ, Rockman HA. Gene deletion screen for cardiomyopathy in adult Drosophila identifies a new notch ligand. Circ Res. 2010; 106:1233-43. [PubMed: 20203305]

Klueg KM, Muskavitch MA. Ligand-receptor interactions and trans-endocytosis of Delta, Serrate and Notch: members of the Notch signalling pathway in Drosophila. J Cell Sci. 1999; 112(Pt 19): 3289-97. [PubMed: 10504334]

Kohno K, Izumi H, Uchiumi T, Ashizuka M, Kuwano M. The pleiotropic functions of the Y-boxbinding protein, YB-1. Bioessays. 2003; 25:691-8. [PubMed: 12815724]

Komatsu H, Chao MY, Larkins-Ford J, Corkins ME, Somers GA, Tucey T, et al. OSM-11 facilitates LIN-12 Notch signaling during Caenorhabditis elegans vulval development. PLoS Biol. 2008; 6:e196. [PubMed: 18700817]

Koo BK, Lim HS, Song R, Yoon MJ, Yoon KJ, Moon JS, et al. Mind bomb 1 is essential for generating functional Notch ligands to activate Notch. Development. 2005; 132:3459-70. [PubMed: 16000382]

Kopan R, Ilagan MX. The canonical Notch signaling pathway: unfolding the activation mechanism. Cell. 2009; 137:216-33. [PubMed: 19379690]

Krebs LT, Xue Y, Norton CR, Shutter JR, Maguire M, Sundberg JP, et al. Notch signaling is essential for vascular morphogenesis in mice. Genes Dev. 2000; 14:1343-52. [PubMed: 10837027]

Lai EC, Deblandre GA, Kintner C, Rubin GM. Drosophila neuralized is a ubiquitin ligase that promotes the internalization and degradation of delta. Dev Cell. 2001; 1:783-94. [PubMed: 11740940] 
Le Borgne R, Bardin A, Schweisguth F. The roles of receptor and ligand endocytosis in regulating Notch signaling. Development. 2005; 132:1751-62. [PubMed: 15790962]

Lee K, Villena JA, Moon YS, Kim KH, Lee S, Kang C, et al. Inhibition of adipogenesis and development of glucose intolerance by soluble preadipocyte factor-1 (Pref-1). J Clin Invest. 2003; 111:453-61. [PubMed: 12588883]

Li JL, Sainson RC, Shi W, Leek R, Harrington LS, Preusser M, et al. Delta-like 4 Notch ligand regulates tumor angiogenesis, improves tumor vascular function, and promotes tumor growth in vivo. Cancer Res. 2007; 67:11244-53. [PubMed: 18056450]

Li L, Krantz ID, Deng Y, Genin A, Banta AB, Collins CC, et al. Alagille syndrome is caused by mutations in human Jagged1, which encodes a ligand for Notch1. Nat Genet. 1997; 16:243-51. [PubMed: 9207788]

Lillis AP, Mikhailenko I, Strickland DK. Beyond endocytosis: LRP function in cell migration, proliferation and vascular permeability. J Thromb Haemost. 2005; 3:1884-93. [PubMed: 16102056]

Limbourg FP, Takeshita K, Radtke F, Bronson RT, Chin MT, Liao JK. Essential role of endothelial Notch1 in angiogenesis. Circulation. 2005; 111:1826-32. [PubMed: 15809373]

Logeat F, Bessia C, Brou C, LeBail O, Jarriault S, Seidah NG, et al. The Notch1 receptor is cleaved constitutively by a furin-like convertase. Proc Natl Acad Sci U S A. 1998; 95:8108-12. [PubMed: 9653148]

Lu L, Chen X, Zhang CW, Yang WL, Wu YJ, Sun L, et al. Morphological and functional characterization of predifferentiation of myelinating glia-like cells from human bone marrow stromal cells through activation of F3/Notch signaling in mouse retina. Stem Cells. 2008; 26:58090. [PubMed: 17975227]

Lubman OY, Ilagan MX, Kopan R, Barrick D. Quantitative dissection of the Notch:CSL interaction: insights into the Notch-mediated transcriptional switch. J Mol Biol. 2007; 365:577-89. [PubMed: 17070841]

Lubman OY, Korolev SV, Kopan R. Anchoring notch genetics and biochemistry; structural analysis of the ankyrin domain sheds light on existing data. Mol Cell. 2004; 13:619-26. [PubMed: 15023333]

McCright B, Gao X, Shen L, Lozier J, Lan Y, Maguire M, et al. Defects in development of the kidney, heart and eye vasculature in mice homozygous for a hypomorphic Notch2 mutation. Development. 2001; 128:491-502. [PubMed: 11171333]

McDaniell R, Warthen DM, Sanchez-Lara PA, Pai A, Krantz ID, Piccoli DA, et al. NOTCH2 mutations cause Alagille syndrome, a heterogeneous disorder of the notch signaling pathway. Am J Hum Genet. 2006; 79:169-73. [PubMed: 16773578]

Meng H, Zhang X, Hankenson KD, Wang MM. Thrombospondin 2 potentiates notch3/jagged1 signaling. J Biol Chem. 2009; 284:7866-74. [PubMed: 19147503]

Meng H, Zhang X, Lee SJ, Strickland DK, Lawrence DA, Wang MM. Low density lipoprotein receptor-related protein-1 (LRP1) regulates thrombospondin-2 (TSP2) enhancement of Notch3 signaling. J Biol Chem. 2010; 285:23047-55. [PubMed: 20472562]

Miyamoto A, Lau R, Hein PW, Shipley JM, Weinmaster G. Microfibrillar proteins MAGP-1 and MAGP-2 induce Notch1 extracellular domain dissociation and receptor activation. J Biol Chem. 2006; 281:10089-97. [PubMed: 16492672]

Nehring LC, Miyamoto A, Hein PW, Weinmaster G, Shipley JM. The extracellular matrix protein MAGP-2 interacts with Jagged1 and induces its shedding from the cell surface. J Biol Chem. 2005; 280:20349-55. [PubMed: 15788413]

Nichol D, Shawber C, Fitch MJ, Bambino K, Sharma A, Kitajewski J, et al. Impaired angiogenesis and altered Notch signaling in mice overexpressing endothelial Egfl7. Blood. 2010; 116:6133-43. [PubMed: 20947685]

Nichols JT, Miyamoto A, Olsen SL, D’Souza B, Yao C, Weinmaster G. DSL ligand endocytosis physically dissociates Notch1 heterodimers before activating proteolysis can occur. J Cell Biol. 2007; 176:445-58. [PubMed: 17296795]

Noguera-Troise I, Daly C, Papadopoulos NJ, Coetzee S, Boland P, Gale NW, et al. Blockade of Dll4 inhibits tumour growth by promoting non-productive angiogenesis. Nature. 2006; 444:1032-7. [PubMed: 17183313] 
Nueda ML, Baladron V, Sanchez-Solana B, Ballesteros MA, Laborda J. The EGF-like protein dlk1 inhibits notch signaling and potentiates adipogenesis of mesenchymal cells. J Mol Biol. 2007; 367:1281-93. [PubMed: 17320900]

Oda T, Elkahloun AG, Pike BL, Okajima K, Krantz ID, Genin A, et al. Mutations in the human Jagged1 gene are responsible for Alagille syndrome. Nat Genet. 1997; 16:235-42. [PubMed: 9207787]

Oh SY, Ellenstein A, Chen CD, Hinman JD, Berg EA, Costello CE, et al. Amyloid precursor protein interacts with notch receptors. J Neurosci Res. 2005; 82:32-42. [PubMed: 16118793]

Okochi M, Steiner H, Fukumori A, Tanii H, Tomita T, Tanaka T, et al. Presenilins mediate a dual intramembranous gamma-secretase cleavage of Notch-1. EMBO J. 2002; 21:5408-16. [PubMed: 12374741]

Opherk C, Duering M, Peters N, Karpinska A, Rosner S, Schneider E, et al. CADASIL mutations enhance spontaneous multimerization of NOTCH3. Hum Mol Genet. 2009; 18:2761-7. [PubMed: 19417009]

Overstreet E, Fitch E, Fischer JA. Fat facets and liquid facets promote Delta endocytosis and Delta signaling in the signaling cells. Development. 2004; 131:5355-66. [PubMed: 15469967]

Parks AL, Klueg KM, Stout JR, Muskavitch MA. Ligand endocytosis drives receptor dissociation and activation in the Notch pathway. Development. 2000; 127:1373-85. [PubMed: 10704384]

Pavlopoulos E, Pitsouli C, Klueg KM, Muskavitch MA, Moschonas NK, Delidakis C. neuralized Encodes a peripheral membrane protein involved in delta signaling and endocytosis. Dev Cell. 2001; 1:807-16. [PubMed: 11740942]

Penner AS, Rock MJ, Kielty CM, Shipley JM. Microfibril-associated glycoprotein-2 interacts with fibrillin-1 and fibrillin-2 suggesting a role for MAGP-2 in elastic fiber assembly. J Biol Chem. 2002; 277:35044-9. [PubMed: 12122015]

Petcherski AG, Kimble J. Mastermind is a putative activator for Notch. Curr Biol. 2000; 10:R471-3. [PubMed: 10898989]

Pierfelice T, Alberi L, Gaiano N. Notch in the vertebrate nervous system: an old dog with new tricks. Neuron. 2011; 69:840-55. [PubMed: 21382546]

Pintar A, De Biasio A, Popovic M, Ivanova N, Pongor S. The intracellular region of Notch ligands: does the tail make the difference? Biol Direct. 2007; 2:19. [PubMed: 17623096]

Raffetseder U, Rauen T, Boor P, Ostendorf T, Hanssen L, Floege J, et al. Extracellular YB-1 blockade in experimental nephritis upregulates Notch-3 receptor expression and signaling. Nephron Exp Nephrol. 2011; 118:e100-8. [PubMed: 21372592]

Rand MD, Grimm LM, Artavanis-Tsakonas S, Patriub V, Blacklow SC, Sklar J, et al. Calcium depletion dissociates and activates heterodimeric notch receptors. Mol Cell Biol. 2000; 20:182535. [PubMed: 10669757]

Rauen T, Raffetseder U, Frye BC, Djudjaj S, Muhlenberg PJ, Eitner F, et al. YB-1 acts as a ligand for Notch-3 receptors and modulates receptor activation. J Biol Chem. 2009; 284:26928-40. [PubMed: 19640841]

Raya A, Kawakami Y, Rodriguez-Esteban C, Ibanes M, Rasskin-Gutman D, Rodriguez-Leon J, et al. Notch activity acts as a sensor for extracellular calcium during vertebrate left-right determination. Nature. 2004; 427:121-8. [PubMed: 14712268]

Renaud O, Simpson P. Scabrous modifies epithelial cell adhesion and extends the range of lateral signalling during development of the spaced bristle pattern in Drosophila. Dev Biol. 2001; 240:361-76. [PubMed: 11784069]

Ridgway J, Zhang G, Wu Y, Stawicki S, Liang WC, Chanthery Y, et al. Inhibition of D114 signalling inhibits tumour growth by deregulating angiogenesis. Nature. 2006; 444:1083-7. [PubMed: 17183323]

Ross DA, Rao PK, Kadesch T. Dual roles for the Notch target gene Hes-1 in the differentiation of 3T3-L1 preadipocytes. Mol Cell Biol. 2004; 24:3505-13. [PubMed: 15060169]

Sakamoto K, Yamaguchi S, Ando R, Miyawaki A, Kabasawa Y, Takagi M, et al. The nephroblastoma overexpressed gene (NOV/ccn3) protein associates with Notch1 extracellular domain and inhibits myoblast differentiation via Notch signaling pathway. J Biol Chem. 2002; 277:29399-405.

[PubMed: 12050162] 
Sanchez-Solana B, Nueda ML, Ruvira MD, Ruiz-Hidalgo MJ, Monsalve EM, Rivero S, et al. The EGF-like proteins DLK1 and DLK2 function as inhibitory non-canonical ligands of NOTCH1 receptor that modulate each other's activities. Biochim Biophys Acta. 2011; 1813:1153-64. [PubMed: 21419176]

Saxena MT, Schroeter EH, Mumm JS, Kopan R. Murine notch homologs (N1-4) undergo presenilindependent proteolysis. J Biol Chem. 2001; 276:40268-73. [PubMed: 11518718]

Schmidt MH, Bicker F, Nikolic I, Meister J, Babuke T, Picuric S, et al. Epidermal growth factor-like domain 7 (EGFL7) modulates Notch signalling and affects neural stem cell renewal. Nat Cell Biol. 2009; 11:873-80. [PubMed: 19503073]

Seugnet L, Simpson P, Haenlin M. Requirement for dynamin during Notch signaling in Drosophila neurogenesis. Dev Biol. 1997; 192:585-98. [PubMed: 9441691]

Seydoux G, Greenwald I. Cell autonomy of lin-12 function in a cell fate decision in C. elegans. Cell. 1989; 57:1237-45. [PubMed: 2736627]

Shimizu K, Chiba S, Kumano K, Hosoya N, Takahashi T, Kanda Y, et al. Mouse jagged1 physically interacts with notch 2 and other notch receptors. Assessment by quantitative methods. J Biol Chem. 1999; 274:32961-9. [PubMed: 10551863]

Shimoyama T, Hiraoka S, Takemoto M, Koshizaka M, Tokuyama H, Tokuyama T, et al. CCN3 inhibits neointimal hyperplasia through modulation of smooth muscle cell growth and migration. Arterioscler Thromb Vasc Biol. 2010; 30:675-82. [PubMed: 20139355]

Takahashi K, Adachi K, Yoshizaki K, Kunimoto S, Kalaria RN, Watanabe A. Mutations in NOTCH3 cause the formation and retention of aggregates in the endoplasmic reticulum, leading to impaired cell proliferation. Hum Mol Genet. 2010; 19:79-89. [PubMed: 19825845]

Tanabe H, Takayama I, Nishiyama T, Shimazaki M, Kii I, Li M, et al. Periostin associates with Notch1 precursor to maintain Notch1 expression under a stress condition in mouse cells. PLoS One. 2010; 5:e12234. [PubMed: 20805882]

Tax FE, Yeargers JJ, Thomas JH. Sequence of $C$. elegans lag-2 reveals a cell-signalling domain shared with Delta and Serrate of Drosophila. Nature. 1994; 368:150-4. [PubMed: 8139658]

Tian X, Hansen D, Schedl T, Skeath JB. Epsin potentiates Notch pathway activity in Drosophila and C. elegans. Development. 2004; 131:5807-15. [PubMed: 15539484]

Tkatchenko TV, Moreno-Rodriguez RA, Conway SJ, Molkentin JD, Markwald RR, Tkatchenko AV. Lack of periostin leads to suppression of Notch1 signaling and calcific aortic valve disease. Physiol Genomics. 2009; 39:160-8. [PubMed: 19723774]

Tsunematsu R, Nakayama K, Oike Y, Nishiyama M, Ishida N, Hatakeyama S, et al. Mouse Fbw7/ Sel-10/Cdc4 is required for notch degradation during vascular development. J Biol Chem. 2004; 279:9417-23. [PubMed: 14672936]

Uyttendaele H, Ho J, Rossant J, Kitajewski J. Vascular patterning defects associated with expression of activated Notch4 in embryonic endothelium. Proc Natl Acad Sci U S A. 2001; 98:5643-8. [PubMed: 11344305]

Wang W, Struhl G. Drosophila Epsin mediates a select endocytic pathway that DSL ligands must enter to activate Notch. Development. 2004; 131:5367-80. [PubMed: 15469974]

Wang Y, Kim KA, Kim JH, Sul HS. Pref-1, a preadipocyte secreted factor that inhibits adipogenesis. J Nutr. 2006; 136:2953-6. [PubMed: 17116701]

Weng AP, Ferrando AA, Lee W, Morris JPt, Silverman LB, Sanchez-Irizarry C, et al. Activating mutations of NOTCH1 in human T cell acute lymphoblastic leukemia. Science. 2004; 306:269_ 71. [PubMed: 15472075]

Wharton KA, Johansen KM, Xu T, Artavanis-Tsakonas S. Nucleotide sequence from the neurogenic locus notch implies a gene product that shares homology with proteins containing EGF-like repeats. Cell. 1985; 43:567-81. [PubMed: 3935325]

Wu L, Aster JC, Blacklow SC, Lake R, Artavanis-Tsakonas S, Griffin JD. MAML1, a human homologue of Drosophila mastermind, is a transcriptional co-activator for NOTCH receptors. Nat Genet. 2000; 26:484-9. [PubMed: 11101851]

Xue Y, Lindsell GX, Norton CE, Chang CR, Hicks B, Gendron-Maguire C, et al. Embryonic lethality and vascular defects in mice lacking the Notch ligand Jagged1. Hum Mol Genet. 1999; 1999:723-30. [PubMed: 10196361] 
Yang Z, Strickland DK, Bornstein P. Extracellular matrix metalloproteinase 2 levels are regulated by the low density lipoprotein-related scavenger receptor and thrombospondin 2. J Biol Chem. 2001; 276:8403-8. [PubMed: 11113133]

Yeh E, Dermer M, Commisso C, Zhou L, McGlade CJ, Boulianne GL. Neuralized functions as an E3 ubiquitin ligase during Drosophila development. Curr Biol. 2001; 11:1675-9. [PubMed: 11696324] 


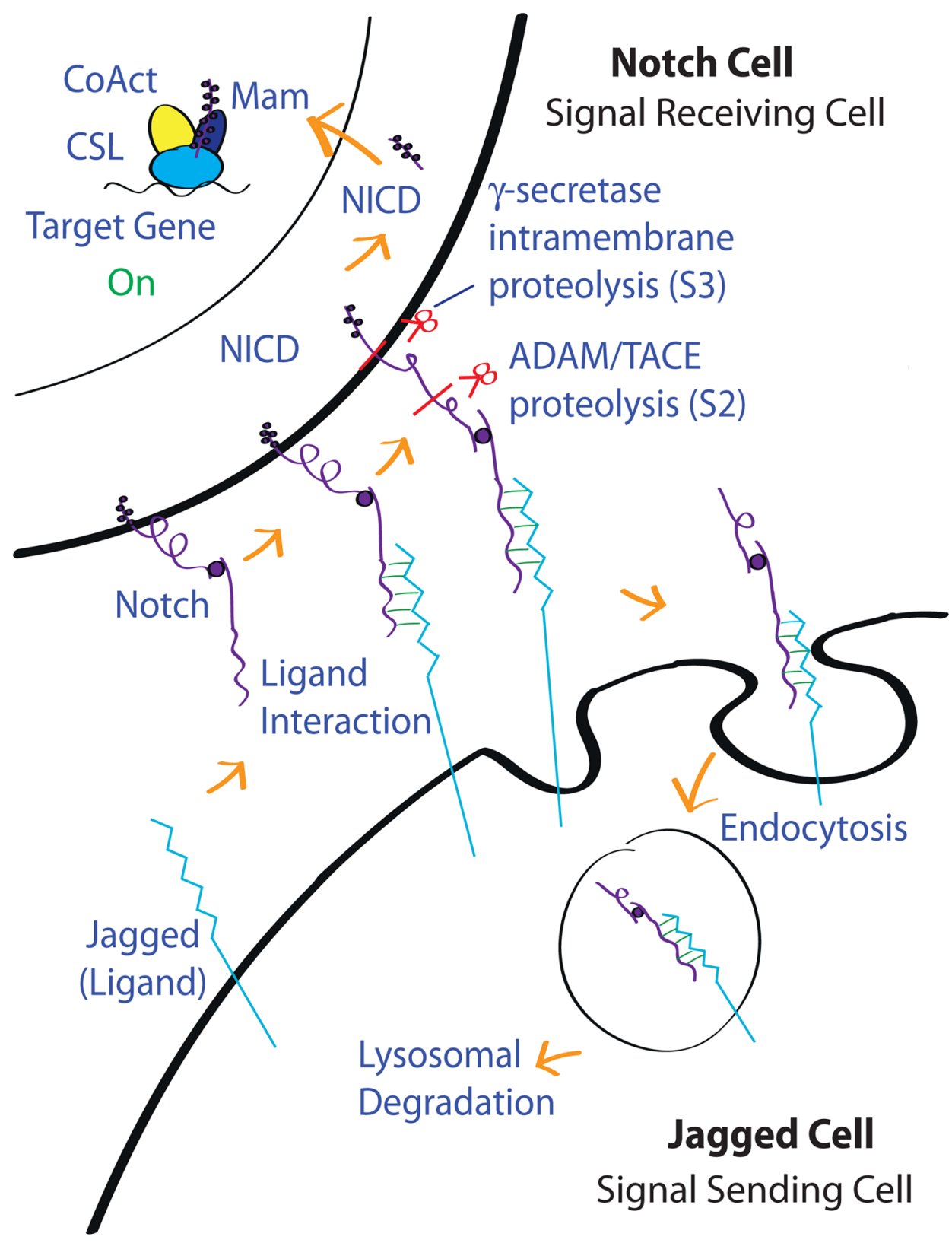

Fig. 1.

Overview of canonical Notch signaling. Notch signaling by DSL ligands (Jagged and Delta in mammalian cells) requires two adjacent cells. The signal receiving cell (top corner) expresses Notch, which in mammals is expressed as a furin-cleaved heterodimer held together by non-covalent interactions. Activation by DSL ligands in the signal sending cell (bottom corner) results in ADAM-mediate proteolysis of Notch, that permits gammasecretase intramembrane cleavage of Notch and migration of the Notch intracellular domain (NICD) to the nucleus, where NICD modulates gene transcription through a CSL/

Mastermind (Mam) dependent complex. Signaling requires endocytosis in the signal sending cell. Forces generated by trans-endocytosis may cause a conformational change in Notch that is required for regulated proteolysis, or, alternatively, may result in receptor dissociation that results in activation. 


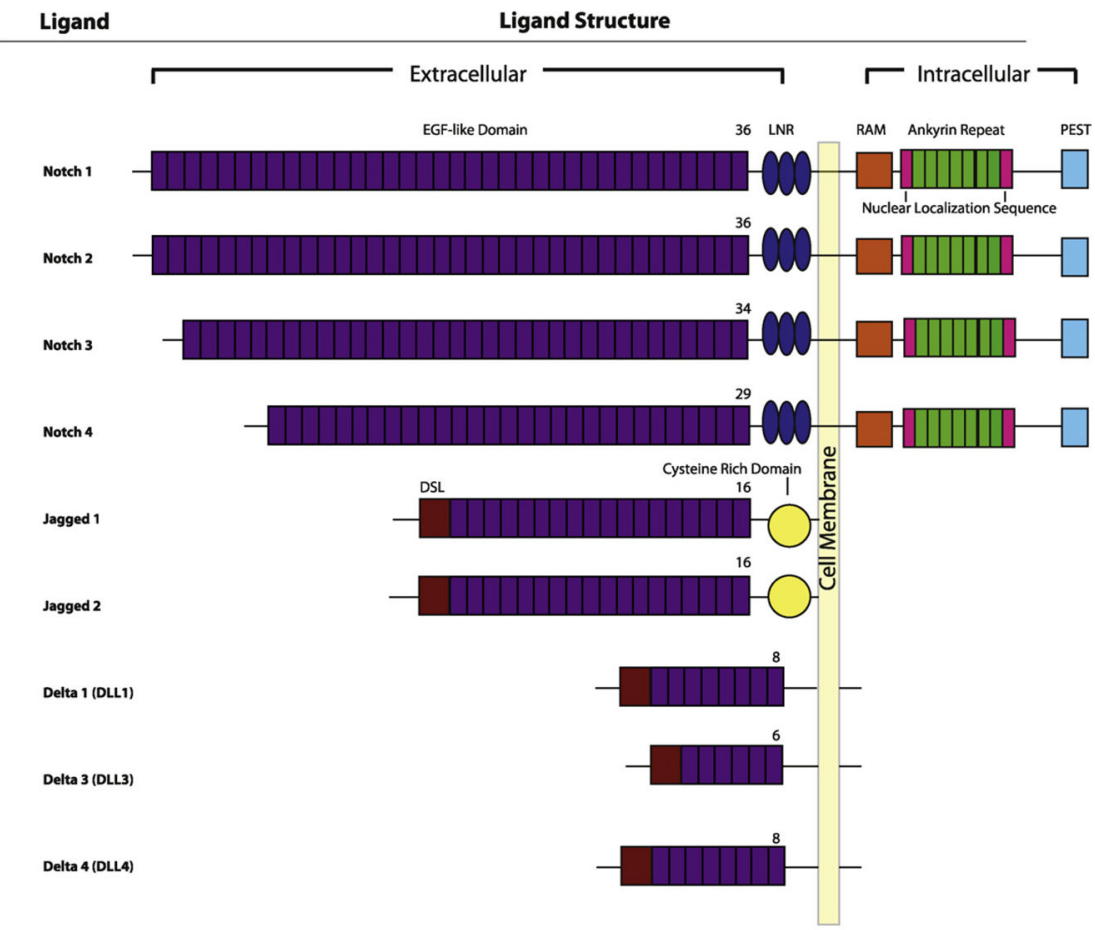

Fig. 2.

Canonical regulators of Notch signaling. Protein structures of canonical Notch pathway receptors and ligands are shown. All proteins contain 6-36 EGF-like domains and are type I transmembrane proteins. The total number of EGF-like domains in each protein is shown above the last EGF-like domain. The four Notch receptors include LIN-12-Notch repeats (LNR) adjacent to the plasma membrane and also contain large modular intracellular domains (NICDs) that act in the nucleus. The ligands all contain DSL domains at the Nterminus. Their intracellular domains are very short. Dll should not be confused with Dlk, a pair of non-canonical ligands (Fig. 3; Section 6.1.1). 


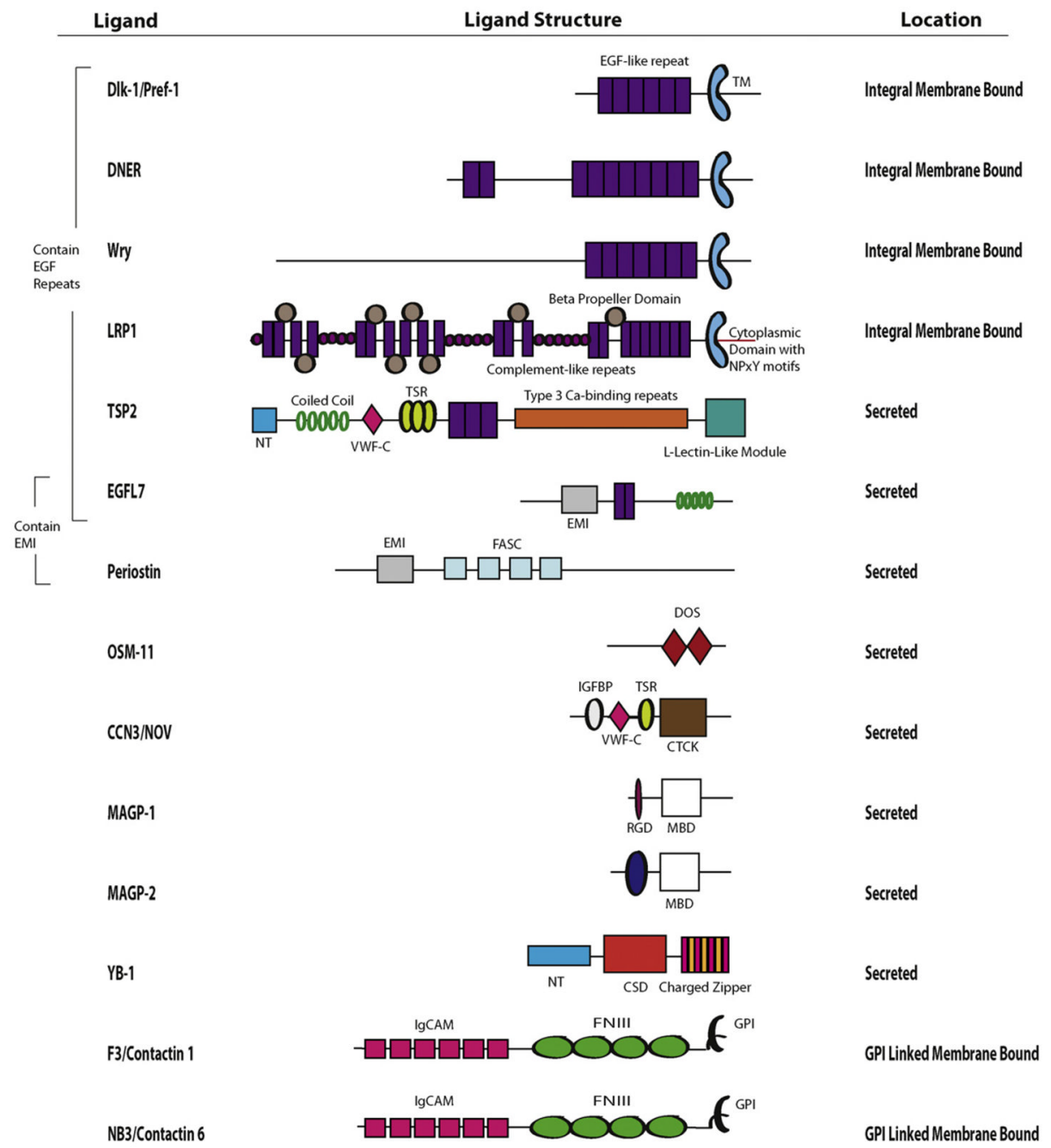

Fig. 3.

Non-canonical regulators of Notch signaling. The proteins depicted are all non-DSL secreted or membrane proteins that interact with and modulate Notch. EGF-like domains constitute a notable feature of many of these proteins. All are drawn to scale with the exception of LRP1. EGF-like domains are tandem epidermal growth factor-like repeats, the TM are the transmembrane domain of the ligand, the NT are the N terminal domains, the VWF-C are the von Willebrand factor C/procollagen domains, the TSR are thrombospondin type 1 domains, the FASC are the fasciclin domains, the EMI are the EMILIN domains, the DOS is the Delta and OSM-11 motif, the IGFBP is the insulin-like growth factor binding protein motif, the CTCK is the carboxy-terminal domain (CT) which contains a cystine-knot motif, the MBD are the matrix binding domains, the RGD is the amino acid sequence (arginine, glycine, aspartic acid), the CSD is the nucleic acid binding domain, the FN3 are the fibronectin type III domains, the IgCAM are conserved domains from the immunoglobulin superfamily of cell adhesion molecules and GPI are the glycosylphophatidylinositol conjugates that link the protein to the plasma membrane. Dlk should not be confused with Dll, which are canonical, DSL-containing Notch ligands (Fig. $2)$. 


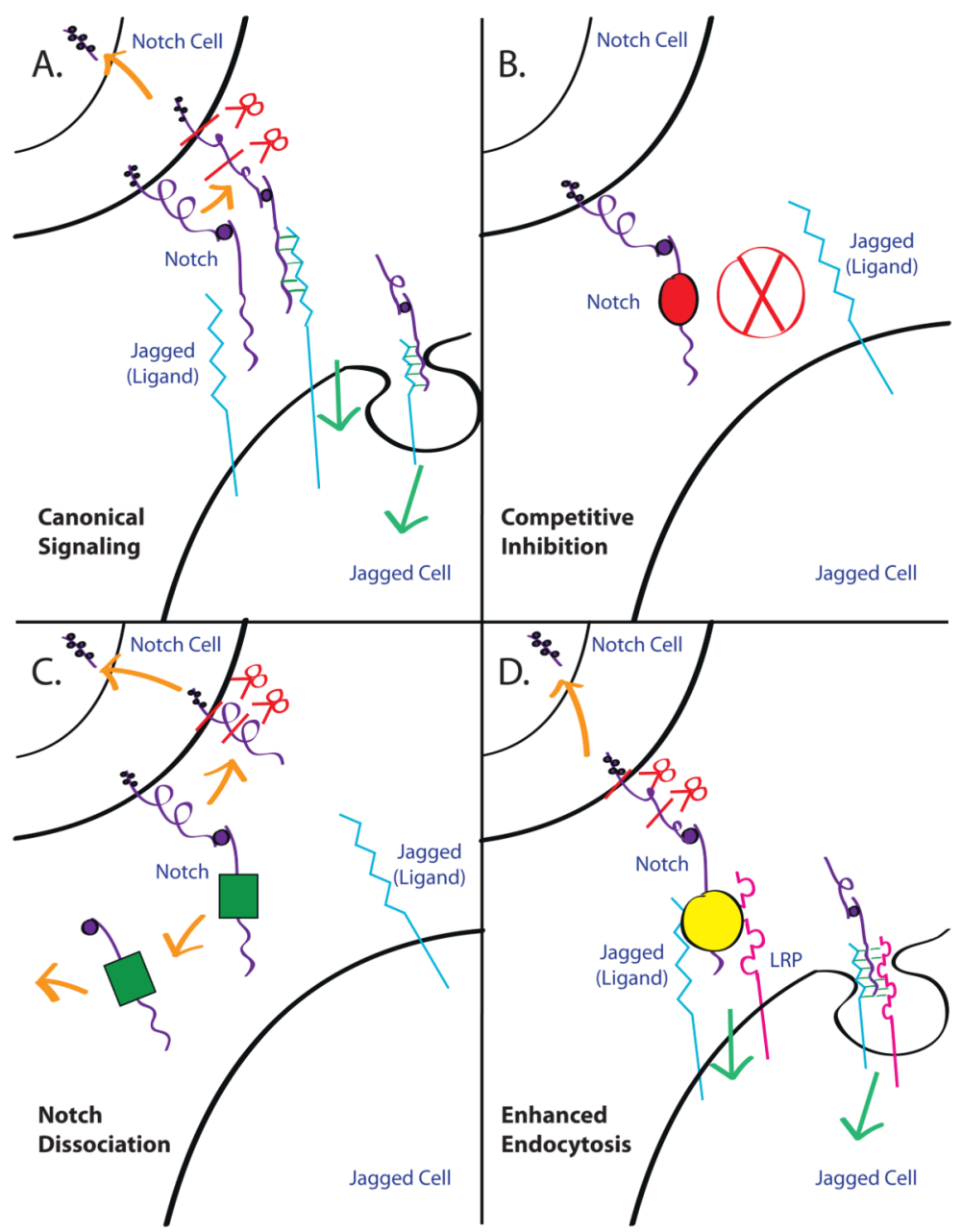

Fig. 4.

Mechanisms of non-canonical Notch modulation. The general mechanism of canonical Notch signaling is shown in (A). Other putative mechanisms of non-canonical regulation are depicted in (B-D). (B) Competitive inhibition of Notch interactions with DSL ligands may underlie the functions of some non-canonical ligands, including Dlk-1 and Dlk-2. (C) Activation of Notch in the absence of DSL ligand may also occur through facilitation of receptor shedding that leads to subsequent generation of NICD. The actions of MAGP proteins are an example of this mechanism of action. (D) Non-canonical ligands may stimulate trans-endocytosis. TSP2 has been shown to bind Notch3, to enhance NotchJagged binding, and to also engage LRP1, an endocytic clearance receptor. The activation of Notch-DSL clearance may be coupled to increased signaling efficiency. 